(2) Open Access Full Text Article

RAPID COMMUNICATION

\title{
Increased Production of Alcohol-Based Hand Rub Solution in Response to COVID-19 and Fire Hazard Potential: Preparedness of Public Hospitals in Addis Ababa, Ethiopia
}

This article was published in the following Dove Press journal:

Risk Management and Healthcare Policy

\author{
Muluken Nigatu Selam (D) \\ Regasa Bayisa ${ }^{2}$ \\ Andualem Ababu (iD ${ }^{2}$ \\ Mahdi Abdella ${ }^{2}$ \\ Edessa Diriba ${ }^{2}$ \\ Minychel Wale 3 \\ Assefa Mulu Baye (D) ${ }^{4}$ \\ 'Department of Pharmaceutics and Social \\ Pharmacy, School of Pharmacy, College of \\ Health Sciences, Addis Ababa University, \\ Addis Ababa, Ethiopia; ${ }^{2}$ Pharmaceutical \\ and Medical Equipment Directorate \\ (PMED), Ministry of Health, Addis Ababa, \\ Ethiopia; ${ }^{3}$ All African Leprosy, \\ Tuberculosis Rehabilitation and Training \\ Centre (ALERT), Addis Ababa, Ethiopia; \\ ${ }^{4}$ Department of Pharmacology and \\ Clinical Pharmacy, School of Pharmacy, \\ College of Health Sciences, Addis Ababa \\ University, Addis Ababa, Ethiopia
}

Correspondence: Muluken Nigatu Selam Department of Pharmaceutics and Social Pharmacy, School of Pharmacy, College of Health Sciences, Addis Ababa University, P. O. Box I I76, Addis Ababa, Ethiopia Tel +25। 912159807

Email muluken.nigatu@aau.edu.et
Background: According to the World Health Organization (WHO), alcohol-based hand rubs (ABHRs) are regarded as the "gold standard" for hand disinfection in healthcare facilities. Local production of ABHRs in health facilities is recommended by WHO due to its availability and affordability reasons. However, fire hazard is a concern in health facilities during ABHRs production, storage, or use from dispensers.

Objective: To evaluate the preparedness of public hospitals found in Addis Ababa, Ethiopia towards potential fire hazards during ABHR production and storage practices.

Methods: A cross-sectional observational study was applied. An assessment checklist was used for evaluating public hospitals' measures taken for the potential fire hazards during ABHR production and storage practice. Statistical Package for Social Sciences (SPSS) version 23 was used for data entry and analysis.

Results: Out of the 13 public hospitals observed in the study, fire extinguishers were not available in more than half of the hospitals' ( 7 hospitals) compounding premises. Also, $57.1 \%$ of the hospitals without fire extinguishers were manufacturing beyond the WHO 50 liters limit of ABHR solution at once under such unfavorable conditions. Moreover, ethanol and the oxidizing agent hydrogen peroxide were not stored separately in eight hospitals.

Conclusion: None of the hospitals were found to be well prepared for the potential risk of fire associated with ABHR solution production and storage practice. Generally, the practices taken by the studied hospitals for preventing the fire risk and minimizing the damage if fire hazards occurred during ABHR production and storage were not satisfactory. On the safety and precautions measures taken for the risk of fire, Tikur Anbessa Specialized Hospital (TASH), Amanuel Mental Specialized Hospital (AMSH), and Eka Kotebe General Hospital (EKGH) showed a relatively better preparedness compared to others. ABHR solutions should be manufactured and stored in a way that limits the risk of ignition and follows standard fire safety measures.

Keywords: ABHR, fire, hospitals, COVID-19, production, storage

\section{Introduction}

Hand hygiene is one of the most important measures to prevent the transmission of healthcare-associated infections (HCAIs) and the current pandemic COVID-19 (Coronavirus Disease-2019) in healthcare settings. In light of the COVID-19 healthcare crisis, the practice of hand hygiene is strongly recommended by washing hands often with soap and water or using hand sanitizers that contain at least $60 \%$ alcohol. $^{1-3}$ 
According to the World Health Organization (WHO), alcohol-based hand rubs (ABHRs) are regarded as the "gold standard" for hand disinfection in healthcare facilities because of its broad antimicrobial spectrum (including SARS-CoV-2), easy availability at the point of care, and general acceptability to health professionals. ${ }^{1,4-6}$ Despite the range of sanitizers in the global market, ABHRs are found to be the most effective and a higher rate of compliance was observed in the healthcare settings. ${ }^{7}$ The availability and affordability problems of ABHR products from the market in low- and middleincome countries (LMICs) can be solved by producing them in the health facilities as indicated by WHO and other literatures. ${ }^{1,5,8-10}$

However, some concerns limit the use of ABHR products for decontamination of hands in the health facilities. Fire hazards are among the concerns with regard to this formulation due to its high alcohol content. ${ }^{11-13}$ Fire incidents may occur in health facilities when ABHR is manufactured, kept in storage areas, or used from dispensers, which would necessitate the implementation of additional safety precautions throughout the facilities. ${ }^{11,14}$ Although the incidence of fires related to ABHR products is very low, the widespread use of ABHR products in the hospital setting warrants heightened awareness of the risks and implementation of safety measures during the production, storage, and use of these products. ${ }^{15,16}$

Currently, following the COVID-19 pandemic, health facilities in Ethiopia have shown an unprecedented demand for alcohol-based hand sanitizers. In order to meet this increased need, significant numbers of hospitals in the country had started their own production of ABHR. But, because of the flammable nature of the product, production and storage of the sanitizers should be done in a careful way to maintain safe conditions. Though the benefits of production and use of ABHR solution in health facilities far outweigh the fire risks, it is suggested that local risk assessments should be undertaken by the facilities. ${ }^{1,17}$ Considering there is a single fire-rescue institution in Addis Ababa (Fire and Emergency Prevention and Rescue Agency) and its limited capacity to rescue the health institutions and others with the desirable urgency after the occurrence of potential fire hazards, the self preparedness of the hospitals for the potential risk of fire during alcohol-based hand sanitizers production is found to be of high importance. Though the local production of ABHR solutions by hospitals is highly appreciated for preventing the spreading of COVID-19 and other infections, a simultaneous due emphasis should be given for the safety measures in the production and storage practices of the product.

The preparedness status of the hospitals that started production of ABHR solutions in Addis Ababa to the potential risk of fire is unknown. Moreover, the evaluations of health institutions for the measures taken for such potential fire hazard risks associated with compounding of hand sanitizers are not common in the literature. Hence, the present observational study aimed at evaluating the preparedness of public hospitals in Addis Ababa to avoid and control the potential risk of fire during the production and storage of ABHR solutions. This study is important to provide valuable baseline information for the health institutions and other small scale hand sanitizer manufacturers for possible safety measures interventions. Furthermore, this study will fill the gap in the literature.

\section{Methods}

\section{Study Setting and Period}

This study was conducted from May 11-26, 2020 in all 13 public hospitals found in Addis Ababa, Ethiopia. The hospitals included in this study were Tikur Anbessa Specialized Hospital (TASH); St Paul Hospital Millennium Medical College (SPHMMC); All African Leprosy, Tuberculosis Rehabilitation and Training Centre Hospital (ALERTH); Eka Kotebe General Hospital (EKGH); St Peter Specialized Hospital (SPSH); Minellik II Referral Hospital (MRH); Yekatit 12 Hospital Medical College (YHMC); Tirunesh Beijing Hospital (TBH); Gandhi Memorial Hospital (GMH); Zewditu Memorial Hospital (ZMH); Addis Ababa Burn, Emergency and Trauma Hospital (AABETH); Amanuel Mental Specialized Hospital (AMSH); and Ras Desta Damtew Memorial Hospital (RDDMH).

\section{Study Design}

An observation-based cross-sectional study was used. The assessment checklist was developed by adopting WHO and other references. ${ }^{13,18-21}$

\section{Eligibility Criteria}

Public hospitals that started ABHR solution production were included in the study.

\section{Sample Size and Sampling Technique}

A purposive sampling technique was used. All the 13 public hospitals found in Addis Ababa having an ABHR solution production unit were included in the study. 


\section{Data Collection Instrument}

The ABHR production units of the hospitals were observed to evaluate the safety of ABHR solutions production and storage practices as per the checklist which was developed in accordance with WHO guideline and other references. ${ }^{13,18-21}$ The observation checklist consisted of nine closed-ended items on the availability of fire extinguishers; storage of starting ingredients and final products; availability of safety and precaution guidelines; and training of personnel on utilization of fire extinguishers.

\section{Data Collection Process and Quality Assurance}

The observers were senior pharmacists trained by expert pharmacists. The selection of data collectors was based on the educational level and experience in ABHR solution production. Training was given for six data collectors about the objectives of the study; regarding taking consent from the hospital management; on the contents of data collection check list; and the safety and precaution measures during ABHR solution production and storage practices for 2 days. Strict supervision by the principal investigators was conducted during data collection; meanwhile, any doubts in the checklist were clarified.

\section{Data Analysis}

Before entry, data was coded, checked for completeness, and accuracy. Then the data was entered and analyzed using Statistical Package for Social Sciences (SPSS) version 23. Descriptive statistics was employed for analyses of data. Categorical variables were described by frequencies and percentages. The preparedness of hospitals for the risk of fire was evaluated by considering the recommended parameters: availability of fire extinguishers in the compounding premise; availability of fire extinguishers in the ethanol storage room; proper placement of fire extinguishers; limited access of unauthorized personnel to the ethanol storage area; limited quantity of ABHR solutions production; separate storage of ethanol and hydrogen peroxide; availability of safety and precaution guidelines; availability of separate storage room for the finished ABHR products; and training of personnel on utilization of fire extinguishers. The hospital is considered to be well prepared for the potential risk of fire associated with the production and storage of ABHR solution when the above parameters are fully considered.
To determine the reliability of the checklist, Cronbach's alpha internal consistency test was used and resulted in an acceptable value, ie, Cronbach's $\alpha=0.65$.

\section{Ethical Approval}

Ethical approval was obtained from the Ethical Review Board of School of Pharmacy, Addis Ababa University (ERB/SOP/213/06/2020). Besides, permission was sought from the respective managers of the hospitals before proceeding with the data collection. The data obtained from the observation was kept confidential and maintained locked throughout the study. The data was recorded in paper forms and only the principal investigators had access to the data.

\section{Results}

As indicated in Table 1, fire extinguishers were not available at the compounding premises (seven hospitals) or in the ethanol storage rooms (eight hospitals). In facilities where fire extinguishers were available (seven hospitals), the areas of their placement were not appropriate in four hospitals. Ethanol and hydrogen peroxide were stored together in the same room in eight hospitals.

\section{Comparison of Hospitals on Safety and Precautions Measures Taken for Risk of Fire}

The studied hospitals were compared for the safety and precautions measures taken on ABHR solution production and storage practices (Figure 1). Three hospitals (TASH, AMSH, and EKGH) had scored the maximum value for the evaluated parameters (scored 6/9), whereas RDDMH had taken none of the measures (scored 0/9).

\section{Discussion}

All hospitals were manufacturing ABHR solutions using ethyl alcohol-based formulation according to WHO guidelines for which the strength of ethanol in the final product is intended to be $80 \%(\mathrm{v} / \mathrm{v}) .{ }^{13}$ Since ethyl alcohol is a flammable liquid which evaporates readily at room temperature into an ignitable vapor, ABHR products should be manufactured and stored away from high temperatures and flames. ${ }^{13,15}$ For this reason, ethanol storage areas and ABHR solution production and storage facilities should be placed away from sources of ignition and ideally air-conditioned and equipped with a fire extinguisher. ${ }^{13,17}$ A study done in German hospitals showed a total of seven 
Table I Safety and Precautions Measures for Risk of Fire in the Production and Storage Practices of ABHR Solution in Public Hospitals Found in Addis Ababa, Ethiopia, $2020(\mathrm{~N}=13)$

\begin{tabular}{|l|l|l|}
\hline \multirow{2}{*}{ Parameters } & Observation \\
\cline { 2 - 3 } & Yes (\%) & No (\%) \\
\hline Fire extinguisher is available at the compounding premise & $6(46.2 \%)$ & $7(53.8 \%)$ \\
Fire extinguisher is available at the ethanol storage room & $5(38.5 \%)$ & $8(61.5 \%)$ \\
Fire extinguisher is properly placed $(\mathrm{N}=7)$ & $3(42.9 \%)$ & $4(57.1 \%)$ \\
Only authorized persons have access to the storage of ethanol & $10(76.9 \%)$ & $3(23.1 \%)$ \\
*More than 50 liters of ABHR solution is produced at once $(\mathrm{N}=7)$ & $4(57.1 \%)$ & $3(42.9 \%)$ \\
The ethanol and hydrogen peroxide are separately stored & $5(38.5 \%)$ & $8(61.5 \%)$ \\
Safety and precaution guidelines are available & $2(15.4 \%)$ & $11(84.6 \%)$ \\
Separate storage room is available for the finished ABHR products & $7(53.8 \%)$ & $6(46.2 \%)$ \\
Personnel trained on proper use of fire extinguisher & $0(0.0 \%)$ & $13(100.0 \%)$ \\
\hline
\end{tabular}

Note: *In hospitals where fire extinguisher was not available at the ABHR production room.

Abbreviation: ABHR, alcohol-based hand rub.

non-severe fire incidents $(0.9 \%$ of hospitals) related to ABHR dispensers. ${ }^{10}$ This result showed the safety of manufacturing and using ABHR products in hospitals should be underlined despite the rare incidences. In the observed hospitals, the location of compounding and ethanol storage rooms were found to be appropriate, which was reasonably away from the potential sources of ignition such as heat sources and electric motors. But fire extinguishers were not available in more than half of the hospitals' (61.5\%) ethanol storage rooms, and $53.8 \%$ did not have fire extinguishers in the compounding premises. This is in contrast with the requirement set by the country regulatory authority which stated that the compounding laboratory shall be equipped with a fire extinguisher. ${ }^{19}$ Even in hospitals with fire extinguishers, most (57.1\%) did not place them in an appropriate place for easy access of it during accidental fire hazards, as they were placed in the confined spaces of the rooms. With the absence of good safety conditions (eg, room ventilation, fire extinguisher, etc), it is suggested not to produce more than 50 liters of ABHR solution per batch to ensure safety in production and storage areas. ${ }^{15}$ In addition, a designated store may be necessary for such highly flammable liquid when storage of more than 50 liters of ethanol or ABHR product is needed. ${ }^{12,16}$ But, the current study revealed that $57.1 \%$ of hospitals, without fire extinguishers, were manufacturing beyond this limit. Aimed at preventing the COVID-19 pandemic and other HCAIs, the hospitals had a production capacity of more than 50 liters of ABHR solution at a time and expect to continue with this capacity

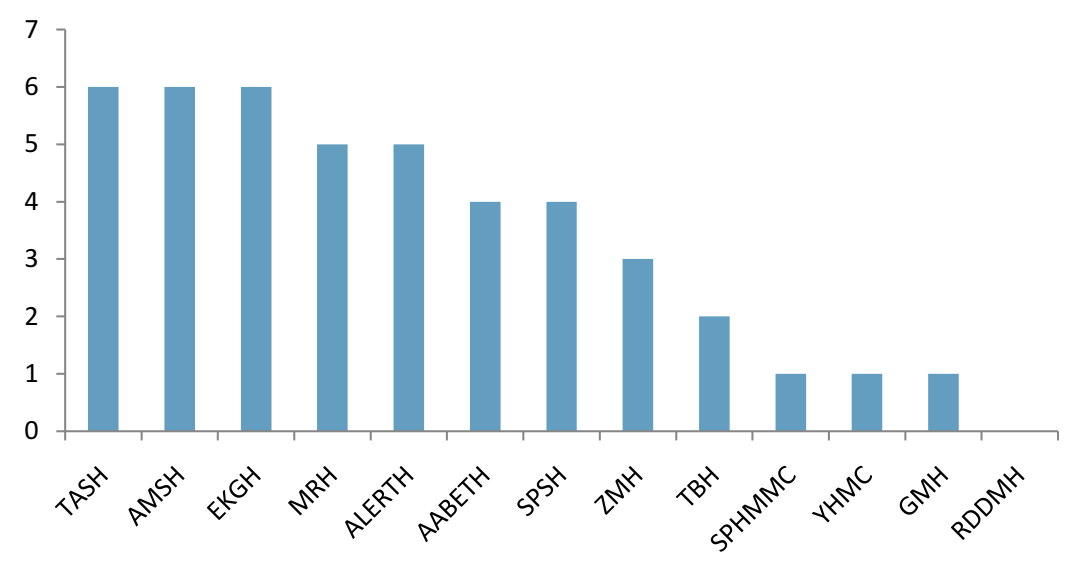

Figure I Total score of public hospitals in Addis Ababa on safety and precaution measures taken for risk of fire for the ABHR solution production and storage practices. Abbreviations: AABETH, Addis Ababa Burn, Emergency and Trauma Hospital; ABHR, alcohol-based hand rub; ALERTH, All African Leprosy, Tuberculosis Rehabilitation and Training Centre Hospital; AMSH, Amanuel Mental Specialized Hospital; EKGH, Eka Kotebe General Hospital; GMH, Gandhi Memorial Hospital; MRH, Minellik II Referral Hospital; RDDMH, Ras Desta Damtew Memorial Hospital; SPHMMC, St Paul Hospital Millennium Medical College; SPSH, St Peter Specialized Hospital; TASH, Tikur Anbessa Specialized Hospital; TBH, Tirunesh Beijing Hospital; YHMC, Yekatit 12 Hospital Medical College; ZMH, Zewditu Memorial Hospital. 
in the future. Hence, the emphasis given by the hospitals towards mitigating the risk of fire should be in line with such a large volume production capacity.

In addition, no naked flames or smoking should be permitted in compounding and ethanol storage areas. ${ }^{13,17}$ Therefore, these areas should be restricted only to authorized persons. With this regard, the majority of hospitals $(76.9 \%)$ had limited the access to these areas for unauthorized individuals either by assigning guards or locking the entrance gates.

Regarding the chemical storage practice, it is advised to keep ethanol and hydrogen peroxide separately, as hydrogen peroxide is a strong oxidizing agent which can initiate or accelerate the combustion of ethanol. ${ }^{20-22}$ From this study, it was shown that these chemicals were stored together in the majority of hospitals $(61.5 \%)$. This storage practice can lead to more dangerous fires and potentially explosions, especially with concentrated hydrogen peroxide $(30 \% \mathrm{w} / \mathrm{v})$, which necessitates their separate storage. The other issue is the premise for production and storage of ABHRs in which an isolated storage room from the compounding area is recommended to minimize the risk of fire. ${ }^{20}$ The current study also revealed that only seven hospitals had a separate storage room for the finished ABHR products.

Moreover, health facilities engaged in production of ABHRs are recommended to have and follow a guideline or standard operating procedure (SOP) prepared for how to execute activities safely in the compounding and storage rooms and appropriate measures to be taken when faults are seen, eg, during spillages of ethanol in the room. ${ }^{13,20}$ Complying with this guideline will not only reduce the risk of fire in production and storage facilities, but also protect persons from the potentially harmful ingredients used in the preparation. ${ }^{20,23}$ However, this study found that the majority of hospitals $(84.6 \%)$ had no such guidelines or SOP for fire safety and other precaution measures. In addition, health facilities should provide regular trainings on the proper operation of fire extinguishers for employees working in the production and storage of alcohol-based sanitizers. ${ }^{24}$ But, personnel in the studied hospitals reported the lack of such trainings given so far.

When a comparison was made among hospitals on the safety and precautions measures taken for risk of fire, TASH, AMSH, and EKGH showed a score of 6 points from the total score ( 9 points) for the considered parameters. These hospitals can relatively prevent the fire hazard associated with ABHR solution production and storage practices compared with the rest and they can also minimize the damage from fire if it occurred. They can further enhance the safety level by fulfilling the remaining measures. In the contrast, SPHMMC, YHMC, and GMH fulfilled only a single parameter considered for the safety and precaution measures, and RDDMH had scored zero. This showed the lack of awareness and/or attention given by these hospitals for the potential risk of fire related to the compounding practice of ABHR solution. These hospitals should take experiences from other hospitals that showed better preparedness for the risk of fire to protect and minimize the damage, since the practice of ABHR solution production has been increasing during the current COVID-19 pandemic.

Fires in the healthcare setting can seriously injure patients, health professionals, and other persons, destroy property, and even cause deaths. The increased use of alcohol-based sanitizers in hospitals, coupled with potential ignition sources, calls for increased awareness of the potential fire hazard and the establishment of fire safety plans in health facilities.

\section{Limitations of the Study}

The finding of the current study may not be extrapolated to other hospitals in the city as a non-probabilistic sampling method was employed. Furthermore, the study did not include private hospitals and other public health facilities or the hospitals in the city that started ABHR solution production following the COVID-19 pandemic.

\section{Conclusions}

More than half of the hospitals did not have fire extinguishers and some of them were not placed in appropriate places in hospitals when they were available. Standard safety guidelines were not available in the majority of hospitals. None of them was found to be well prepared for the potential risk of fire associated with ABHR solution production and storage practice. Generally, the activities and measures taken by the studied hospitals for preventing the fire risk and minimizing the damage if fire hazards occurred during $\mathrm{ABHR}$ production and storage were not satisfactory. A coordinated personnel approach is required to control fire risks of ABHRs in health facilities and involves the risk assessment at production, storage, and points of use. Moreover, as the use of ABHRs is found to be increased throughout the hospitals, the appropriate use of a particular-sized dispensing unit in the 
hospital wards should be evaluated to reduce the risk of fire hazards.

\section{Data-Sharing Statement}

All data are included within the manuscript. All data generated or analyzed during this study are included in the manuscript and supplementary file 1 (STROBE checklist for cross-sectional observational studies).

\section{Acknowledgment}

The authors would like to thank staff of the pharmacy compounding units of all the studied hospitals for their cooperation.

\section{Funding}

This study was supported by Ministry of Health, Ethiopia.

\section{Disclosure}

The authors declare that they have no competing interests.

\section{References}

1. World Health Organization. WHO guidelines on hand hygiene in health care; 2009. Available from: https://apps.who.int/iris/bitstream/ handle/10665/44102/9789241597906_eng.pdf?sequence=1. Accessed July 21, 2020.

2. World Health Organization. Interim recommendations on obligatory hand hygiene against transmission of COVID-19; 2020. Available from: https://www.who.int/publications/m/item/interim-

recommendations-on-obligatory-hand-hygiene-against-transmission-of -covid-19. Accessed August 28, 2020.

3. Center for Disease Control and Prevention (CDC). Coronavirus disease 2019 (COVID-19). How to protect yourself \& others. Available from: https://www.cdc.gov/coronavirus/2019-ncov/prevent-gettingsick/prevention.html. Accessed August 28, 2020.

4. Li Y, Wang Y, Yan D, et al. Self-reported hand hygiene practices, and feasibility and acceptability of alcohol-based hand rubs among village healthcare workers in Inner Mongolia, China. J Hosp Infect. 2015;90 (4):338-343. doi:10.1016/j.jhin.2015.04.006

5. Bauer-Savage J, Pittet D, Kim K, et al. Local production of WHO-recommended alcohol-based handrubs: feasibility, advantages, barriers and costs. Bull World Health Organ. 2013;91(12):963-969. doi:10.2471/BLT.12.117085

6. Kampf G. Potential role of inanimate surfaces for the spread of coronaviruses and their inactivation with disinfectant agents. Infect Prev Pract. 2020;2(2):100044. doi:10.1016/j.infpip.2020.100044

7. Jairoun AA, Al-Hemyari SS, Shahwan M. The pandemic of COVID-19 and its implications for the purity and authenticity of alcohol-based hand sanitizers: the health risks associated with falsified sanitizers and recommendations for regulatory and public health bodies. Res Social Adm Pharm. 2020;S1551-7411.

8. Allegranzi B, Pittet D. Healthcare-associated infection in developing countries: simple solutions to meet complex challenges. Infect Control Hosp Epidemiol. 2007;28(12):1323-1327.
9. Saito H, Inoue K, Ditai J, et al. Alcohol-based hand rub and incidence of healthcare associated infections in a rural regional referral and teaching hospital in Uganda ('WardGel' study). Antimicrob Resist Infect Control. 2017;6(1):1-12. doi:10.1186/s13756-017-0287-8

10. Kama-Kieghe S, Duong A Local production of alcohol based hand rubs (ABHR) in Nigeria - the way of the future? 2016. Available from: https://infectioncontrol.tips/2016/03/05/abhr/. Accessed May 08, 2020.

11. Kramer A, Kampf G. Hand rub-associated fire incidents during 25,038 hospital-years in Germany. Infect Control Hosp Epidemiol. 2007;28(6):745-746. doi:10.1086/517953

12. Jing JLJ, Yi TP, Bose RJC, et al. Hand sanitizers: a review on formulation aspects, adverse effects, and regulations. Int J Environ Res Public Health. 2020;17(9):3326. doi:10.3390/ijerph17093326

13. World Health Organization. Guide to local production: WHO-recommended handrub formulations; 2010. Available from: https://www.who.int/gpsc/5may/Guide_to_Local_Production.pdf. Accessed March 04, 2020.

14. Federal Register. Medicare and medicaid programs; fire safety requirements for certain health care facilities; 2016. Available from: https://www.govinfo.gov/content/pkg/FR-2016-05-04/pdf/201610043.pdf. Accessed August 30, 2020.

15. Center for Disease Control and Prevention (CDC). Fire safety and Alcohol-Based Hand Sanitizer (ABHS). Available from: https://www. cdc.gov/handhygiene/firesafety/index.html. Accessed August 30, 2020.

16. Prasad R, Quezado Z, Andre AS, et al. Fires in the operating room and intensive care unit: awareness is the key to prevention. Anesth Analg. 2006;102:172-174. doi:10.1213/01.ane.0000183641.09008.f2

17. World Health organization. Alcohol-based handrub risks/hazards. Available from: https://www.who.int/gpsc/tools/faqs/abhr2/en/. Accessed August 28, 2020.

18. Ministry of Health- Ethiopia. Health facility alcohol based hand rub preparation standard operating procedure; 2019. Available from: http://www.moh.gov.et/ejcc/am/HEALTH\%20FACILITY\% 20 A L C O H O L \% 20 B A S E D \% 20 H A N D \% 20 R U B \% 20 PREPARATION $\% 20$ STANDARD $\% 20$ OPERATING $\%$ 20PROCEDUR. Accessed February 10, 2020.

19. Drug Administration and Control Authority (DACA) of Ethiopia. Standards for the establishment and practice of pharmaceutical compounding laboratory; 2002. Available from: http://www.ethiopianre view.com/pdf/001/Labcomp.pdf. Accessed March 06, 2020.

20. Government of Western Australia. Department of Mines, Industry Regulation and Safety. Safety considerations when manufacturing alcohol-based hand sanitizers; 2020. Available from:http://www. dmp.wa.gov.au/Documents/Dangerous-Goods/DGS_SB_0220.pdf. Accessed April 27, 2020.

21. Safe work Australia. Managing risks of storing chemicals in the workplace. Guidance material; 2018. Available from: https://www. safeworkaustralia.gov.au/doc/managing-risks-storing-chemicalsworkplace. Accessed January 18, 2020.

22. Accord Australasia. Alcohol-Based Hand Sanitiser Manufacturing and Transport. Available from: https://accord.asn.au/wp-content /uploads/2020/04/Alcohol-Hand-sanitiser-safety-DG-V2.0-16Apr20-. pdf. Accessed February 10, 2020.

23. Impact Fire. What you need to know about fire safety and alcohol-based hand sanitizer; 2020. Available from: https:// resources.impactfireservices.com/what-you-need-to-know-about-firesafety-and-alcohol-based-hand-sanitizer. Accessed August 28, 2020.

24. Impact Fire. Who is responsible for fire safety in the workplace? 2019. Available from: https://resources.impactfireservices.com/who-isresponsible-for-fire-safety-in-the-workplace. Accessed August 28, 2020. 


\section{Publish your work in this journal}

Risk Management and Healthcare Policy is an international, peerreviewed, open access journal focusing on all aspects of public health, policy, and preventative measures to promote good health and improve morbidity and mortality in the population. The journal welcomes submitted papers covering original research, basic science, clinical \& epidemiological studies, reviews and evaluations, guidelines, expert opinion and commentary, case reports and extended reports. The manuscript management system is completely online and includes a very quick and fair peer-review system, which is all easy to use. Visit http://www.dovepress.com/testimonials.php to read real quotes from published authors. 